evaluated, which included pneumatic, dual-lead vented electric, and single-lead vented electric devices, although there have been changes in criteria for device implantation, selection of candidates, and the devices themselves. However, we pursued this approach because of the relatively small number of patients in each individual device category and the lack of statistical power and because the criteria for device implantation have always been similar for male and female patients.

\section{References}

1. Steingart RM, Packer M, Hamm P, Coglianese ME, Gersh B, Geltman EM, et al. Sex differences in the management of coronary artery disease. Survival and Ventricular Enlargement Investigators. $N$ Engl J Med. 1991;325(4):226-30.

2. Ayanian JZ, Epstein AM. Differences in the use of procedures between women and men hospitalized for coronary heart disease. $N$ Engl J Med. 1991;325(4):221-5.

3. Rao V, Oz MC, Flannery MA, Catanese KA, Argenziano M, Naka Y. Revised screening scale to predict survival after insertion of a left ventricular assist device. J Thorac Cardiovasc Surg. 2003;125(4):85562.

4. Roger VL, Farkouh ME, Weston SA, Reeder GS, Jacobsen SJ, Zinsmeister AR, et al. Sex differences in evaluation and outcome of unstable angina. JAMA. 2000;283(5):646-52.

5. Mosca L, Manson JE, Sutherland SE, Langer RD, Manolio T, BarrettConnor E. Cardiovascular disease in women: a statement for healthcare professionals from the American Heart Association Writing Group. Circulation. 1997;96(7):2468-82.

\title{
Assessment of coronary flow reserve with a Doppler guide wire in children with tetralogy of Fallot before and after surgical operation
}

Kentaro Toiyama, MD, ${ }^{a}$ Isao Shiraishi, MD, ${ }^{a}$ Tatsujiro Oka, MD, ${ }^{a}$ Ayumi Kawakita, MD, ${ }^{a}$ Naoya Iwasaki, MD, ${ }^{a}$ Toshikatsu Tanaka, MD, ${ }^{a}$ Koichi Sakata, MD, ${ }^{a}$ Toshiyuki Itoi, MD, ${ }^{a}$ Keisuke Shuntoh, MD, ${ }^{\mathrm{b}}$ Masaaki Yamagishi, MD, ${ }^{\mathrm{b}}$ and Kenji Hamaoka, MD, ${ }^{a}$ Kyoto, Japan

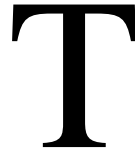
etralogy of Fallot (TOF) is one of the most common cyanotic congenital heart diseases in childhood. Before surgical repair, patients with TOF are exposed to right ventricular (RV) pressure overload, which induces RV hypertrophy. Although cardiac hypertrophy has been shown to induce impaired coronary microcirculation and cardiac dysfunction in adults, ${ }^{1}$ it is uncertain whether RV hypertrophy induces impaired coronary microcirculation in patients with TOF. The purpose of this study was to evaluate the relationship between the $\mathrm{RV}$ pressure overload and the coronary flow reserve (CFR) in TOF and to search for the best way to prevent life-threatening events.

\section{Methods}

The study population consisted of 14 patients with TOF ( 8 male and 6 female, Table 1). They were divided into three groups: preoperative $(n=4)$, early postoperative $(n=6)$, and late post-

\footnotetext{
From the Departments of Pediatrics ${ }^{\mathrm{a}}$ and Pediatric Cardiovascular Surgery, Children's Research Hospital, Kyoto Prefectural University of Medicine, Kyoto, Japan.

Received for publication Jan 7, 2003; accepted for publication June 19, 2003.

Address for reprints: Kenji Hamaoka, MD, Department of Pediatrics, Children's Research Hospital, Kyoto Prefectural University of Medicine, Kawaramachi-Hirokoji, Kamigyo, Kyoto, Japan 602-8566 (E-mail: khamaoka@koto.kpu-m.ac.jp).

J Thorac Cardiovasc Surg 2004;127:1195-7

$0022-5223 / \$ 30.00$

Copyright $\odot 2004$ by The American Association for Thoracic Surgery doi:10.1016/j.jtcvs.2003.06.013
}

\section{TABLE 1. Patient characteristics}

\begin{tabular}{lccc}
\hline Groups & $\begin{array}{c}\text { Preoperative } \\
(\mathbf{n}=\mathbf{4})\end{array}$ & $\begin{array}{c}\text { Early } \\
\text { postoperative } \\
(\mathbf{n = 6 )}\end{array}$ & $\begin{array}{c}\text { Late } \\
\text { postoperative } \\
(\mathbf{n}=\mathbf{4})\end{array}$ \\
\hline Age (y) & $1.25 \pm 0.17$ & $2.56 \pm 0.83$ & $12.9 \pm 2.99$ \\
Sex (male/female) & $2: 2$ & $2: 4$ & $4: 0$ \\
RV pressure (mm Hg) & $93.3 \pm 9.24$ & $49.4 \pm 16.2^{*}$ & $53.0 \pm 11.4^{*}$ \\
PA pressure (mm Hg) & $14.7 \pm 5.7$ & $20.7 \pm 4.0$ & $20.3 \pm 7.8$ \\
RV-PA pressure & $78.7 \pm 9.23$ & $26.2 \pm 18.1^{*}$ & $32.8 \pm 8.42^{*}$ \\
$\quad$ gradient (mm Hg) & & $1.14 \pm 0.34$ & $11.0 \pm 2.01$ \\
$\begin{array}{c}\text { Interval from } \\
\quad \text { operation (y) }\end{array}$ & - & & \\
Pulmonary & & & \\
$\quad$ insufficiency & - & &
\end{tabular}

Data are presented as mean \pm SD. $P A$, Pulmonary artery; \pm , slight regurgitation; + , mild regurgitation.

${ }^{*} P<.05$ versus preoperative value.

operative $(n=4)$. After the radical operation, the RV pressure of these patients improved significantly. Echocardiographic examination after the surgical repair revealed mild to moderate pulmonary regurgitation with mild RV dilatation. The control patients consisted of 16 age-matched patients with Kawasaki disease who had shown normal coronary arteries and normal ventricular function on angiography. ${ }^{2,3}$ They were divided into two groups: younger than 6 years for the preoperative and the early postoperative groups and 6 to 16 years old for the late postoperative group. The Doppler guide wire used in this study was a flexible, 0.018-inch guide wire with a 12-MHz piezoelectric ultrasound transducer (FloWire; Cardiometrics Inc, Mountain View, Calif). Blood flow velocity was 


\section{A: LAD (0-6 years old)}

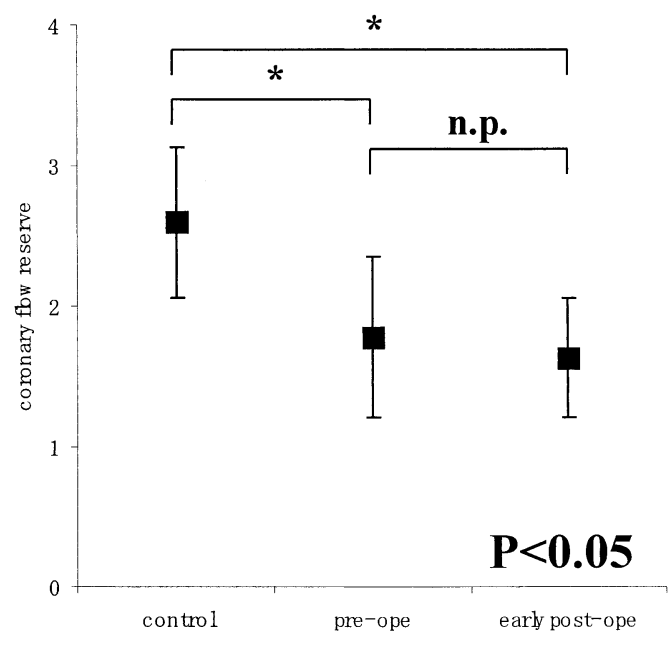

\section{B: LAD (6-16 years old)}

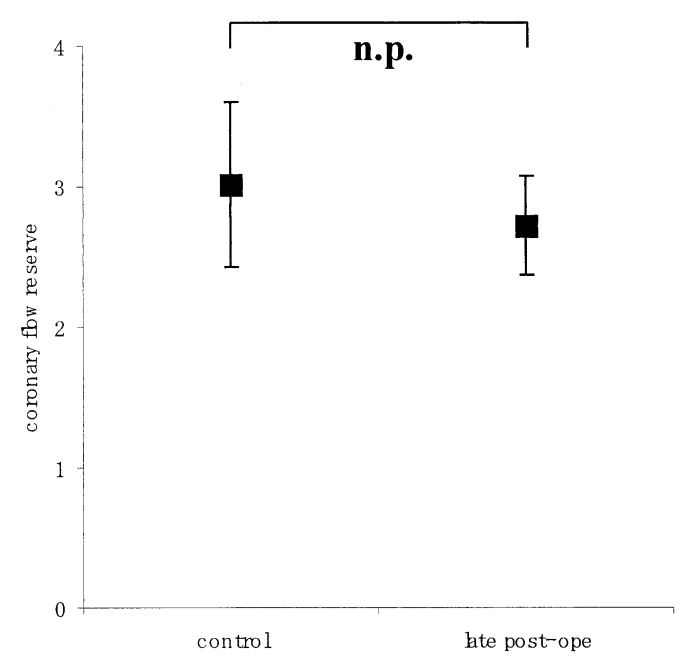

\section{C: RCA (0-6 years old)}

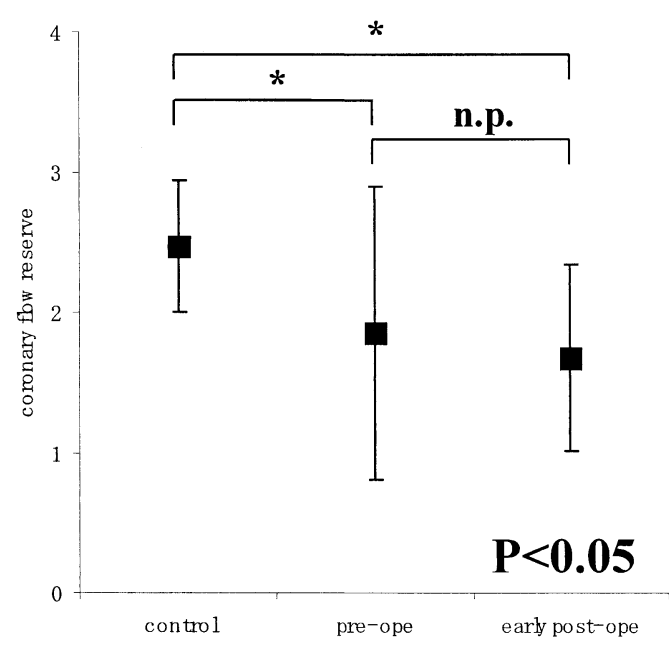

\section{D: RCA (6-16 years old)}

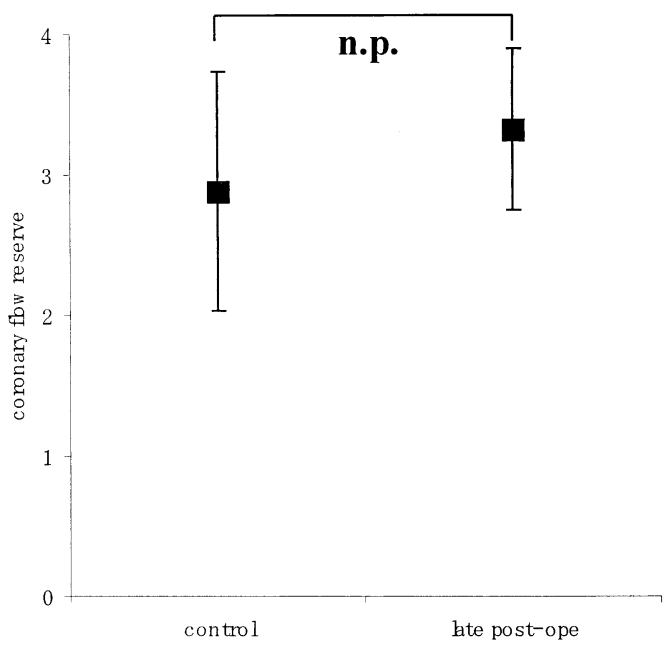

Figure 1. CFR in children with TOF. A and B, CFR data from left anterior descending coronary artery (LAD). C and D, CFR data from right coronary artery (RCA). A and C, Preoperative (pre-ope) and early postoperative (post-ope) groups, which consisted of 0 - to 6-year-olds. Control group was age matched for TOF group. B and D: Late postoperative group, which consisted of 6- to 16-year-olds. Control group was age matched for TOF group. Asterisk, Statistical significance between 2 groups $(P<.05)$; n.p., no statistical significance between the 2 groups.

determined by the Doppler frequency shift. Data analysis was performed by FloMap No. 5500 (JOMED Inc, Rancho Cordova, Calif).

After completion of coronary angiography, the Doppler guide wire was carefully advanced through a guiding catheter into the left anterior descending coronary artery (segment 6 ) and the right coronary artery (segment 2 ). ${ }^{2}$ The position of the guide wire was adjusted to obtain a maximal flow velocity signal. After the resting average peak velocity was measured, adenosine triphosphate (1.0 $\mu \mathrm{g} / \mathrm{kg}$ ) was rapidly injected into each coronary artery through the guiding catheter. CFR was defined as the ratio of hyperemia to the basal average peak velocity. ${ }^{2}$ Results are shown as mean \pm SD. Multiple comparison studies were performed by the analysis of variance test, and statistical significance was defined as $P<.05$. 


\section{Results}

Left anterior descending coronary artery (segment 6). CFR in the preoperative group $(1.88 \pm 0.57)$ was significantly lower than that in the control group $(2.56 \pm 0.39, P<.05)$. CFR in the early postoperative group $(1.60 \pm 0.41)$ was also lower than that in the control group (2.56 $\pm 0.39, P<.05$; Figure $1, A)$. However, CFR in the late postoperative group $(2.82 \pm 0.83)$ was significantly higher than that in the preoperative and early postoperative groups $(P<.05)$. There was no significant difference between the late postoperative group and the control group $(3.01 \pm 0.90$; Figure 1, $B)$.

Right coronary artery (segment 2). CFR in the preoperative group $(1.85 \pm 0.58)$ was significantly lower than that in the control group $(2.30 \pm 0.44, P<.05)$. CFR in the early postoperative group $(1.72 \pm 0.48)$ was also statistically lower than that in the control group $(2.30 \pm 0.44, P<.05$; Figure $1, C)$. CFR in the late postoperative group $(2.95 \pm 0.58)$, however, was significantly higher than that in the preoperative and early postoperative groups. There was no significant difference between the late postoperative group and the control group $(3.32 \pm 0.48$; Figure $1, D)$.

\section{Discussion}

Although long-term prognosis of patients with TOF has ]improved markedly, some life-threatening events have been reported after the radical operation. These patients appear to die of serious ventricular arrhythmias induced by residual RV pressure overload or abnormal coronary microcirculation. ${ }^{4}$ In adult patients with cardiac hypertrophy, impaired coronary microcirculation has been reported as an etiology of lethal ventricular arrhythmias. ${ }^{5}$ One possible mechanism is an imbalance of oxygen delivery and consumption in the hypertrophied heart where the coronary microcirculation is insufficient to supply oxygen to enlarged cardiomyocytes. In the hypertrophied heart, the coronary arterioles are already dilated even in the resting state. Coronary flow does not increase after the administration of adenosine triphosphate, resulting in the decrease of CFR. In the same manner, impaired coronary microcirculation appears to occur during exercise; this may induce dangerous ventricular arrhythmias in patients with TOF. ${ }^{6}$ These speculations are supported by the results that CFR is negatively correlated with the RV pressure, rather than the RV volume.

In this study we showed that CFRs at the right coronary artery and left anterior descending coronary arteries of patients with TOF were low in the preoperative and early postoperative periods and that the CFR significantly improved in the late postoperative period. Early radical operation for TOF is recommended, to avoid the prolonged exposure of RV pressure overload and the resultant impaired coronary microcirculation. Careful observation is also recommended during the preoperative and early postoperative periods, because the RV myocardium is exposed to the impaired CFR.

\section{References}

1. Roberto L, Roberto G. Coronary vasodilator reserve is impaired in patients with hypertrophic cardiomyopathy and left ventricular dysfunction. Am Heart J. 1998;136:972-81.

2. Hamaoka K, Onouchi Z, Ohmochi Y, Sakata K. Coronary arterial flow-velocity dynamics in children with angiographically normal coronary arteries. Circulation. 1995;92:2457-62.

3. Hamaoka K, Onouchi Z, Kamiya Y, Sakata K. Evaluation of coronary flow velocity dynamics and flow researve in patients with Kawasaki disease by means of Doppler guide wire. J Am Coll Cardiol. 1998;31: $833-40$.

4. Gatzoulis MA, Balaji S, Webber SA. Risk factors for arrhythmia and sudden cardiac death late after repair of tetralogy of Fallot: a multicentre study. Lancet. 2000;356:975-81.

5. Brush JE, Cannon RO. Angina due to coronary microvascular disease in hypertensive patients without left ventricular hypertrophy. $N$ Engl J Med. 1988;319:1302-7.

6. Iacopo O, Barry JM. Prognostic value of systemic blood pressure response during exercise in a community-based patient population with hypertrophic cardiomyopathy. J Am Coll Cardiol. 1999;33:2044-51. 